\title{
Sociální vědy
}

UDC 316.012

DOI: $10.24045 /$ pp.2017.4.4

\section{DIGITIZATION AND ITS IMPACT ON EMPLOYMENT IN GLOBALIZED WORLD}

\author{
E. Kasparova
}

\author{
Ph.Dr., \\ e-mail: kasparov@vse.cz, \\ University of Economics in Prague, \\ Prague, Czech Republic
}

\begin{abstract}
The process of globalization brings the emergence of many new phenomena, which affect human daily life. The very important and very frequent one is digitization of almost every aspect of life of each of us as human beings. Digitization in relationship with globalization increases the speed of interconnectivity and worldwide interactivity not only among people but among robots, digital systems and technologies as well. We find ourselves in the period of cyber-physical systems creation and usage. This new period called 4.0 industrial revolution brings new opportunities and challenges as well as new threats and risks in the present and the future labour market and of course employment. The paper focuses on employment and its perspectives in 4.0 industrial revolution.
\end{abstract}

Keywords: globalization; digitization; labour market; technologies; employment; education; training.

\section{Introduction}

The Levin's Institute defines globalization as a process of interaction and integration among the people, companies, and governments of different nations, a process driven by international trade and investment and aided by information technology. This process has effects on the environment, on culture, on political systems, on economic development and prosperity, and on human physical well-being in societies around the world [13].

Business dictionary sees the main purpose of globalization in the worldwide economic, financial, trade, and communication integration and describes the process as a worldwide movement toward this integration. According to a Business Dictionary, Globalization implies the opening of local and nationalistic perspectives to a broader outlook of an interconnected

In addition, interdependent world with free transfer of capital, goods, and services across national frontiers. On the other hand, the definition warns that it does not include unhindered movement of labour and, as suggested by some economists, may hurt smaller or fragile economies if applied indiscriminately [14].

The scale of definitions is quite large but most of them pay attention to the worldwide interconnectivity and interactivity of the different areas of economy, political and social life of the people often enabled by new technologies in the process of digitization. The world has become extremely connected, interdependent and complex, causing rapid global change, hardly predictable system dynamics, and uncontrollable situations [7].

Therefore, it is important to understand the nature and significance of the digitization to be well prepared to react adequately to its impact. There are requirements for a quick process of digitization in all branches of industry.

From the perspective of Europe, industry is one of the pillars of the European economy - the manufacturing sector in the European Union accounts for 2 million en- 
terprises, 33 million jobs and $60 \%$ of productivity growth. The present EU strategy supports the development of new-generation information technologies such as the Internet of Things (IoT), cloud computing, big data and data analytics, robotics and 3D printing. These technologies open new perspectives for industry to become more adventurous, more efficient, to improve processes and to develop innovative products and services. As European Commission refers, recent studies estimate that digitization of products and services can add more than $€ 110$ billion of annual revenue in Europe in the next five years [4].

\section{4.0 Industrial Revolution}

Technological development is one of the core characteristics of an industrial epoch from its early beginning. The previous stages increased new perspectives in manufacturing, in business and of course in social and political life as well. New horizons had been opened for humankind and the speed and amount of changes affected traditional social life in all its aspects.

The Industrial Revolution is a milestone of society development in which machines changed people's way of life as well as their methods of manufacture. The most important changes during the centuries had affected first the human work by the invention of machines to do the work of hand tools, the use of steam, and later of other kinds of power, in place of the muscles of human beings and of animals; and the adoption of the factory system [6].

On the other hand, the speed of current breakthroughs has no historical precedent. When compared with previous industrial revolutions, the Fourth is evolving at an exponential rather than a linear pace. Digitalization changes everything very fast.

The possibilities of billions of people connected by mobile devices, with unprece- dented processing power, storage capacity, and access to knowledge, are unlimited. In addition, these possibilities will be multiplied by emerging technology breakthroughs in fields such as artificial intelligence, robotics, the Internet of Things, autonomous vehicles, 3-D printing, nanotechnology, biotechnology, materials science, energy storage, and quantum computing [11].

Three core elements of Industry 4.0 identified by Siemens show the main character of technological change [10]. The fusion of virtual and real world, which means the integration of product design and production engineering, based on a common digital enterprise platform. Cyber physical systems, which are composed of diverse constituent parts that collaborate to create some global behaviour and increase M2M communication. These constituents include software systems, communications technology, and sensors/actuators that interact with the real world, often including embedded technologies and the dynamic production network, which allows that humans and autonomous machines will work closely together [3]. Autonomous machines will understand human gestures and behaviours and will employ learning to optimize their own operation [10].

\section{Employment in Digitalized World}

The Fourth Industrial Revolution brings a lot of new opportunities as well as risks for companies. One of the most prominent risks can be seen in the field of employment. Klaus Schwab (2016) writes, "The Fourth Industrial Revolution has the potential to empower individuals and communities, as it creates new opportunities for economic, social, and personal development. But it also could lead to the marginalization of some groups, exacerbate inequality, create new security risks, and undermine human relationships."

Paradigmata poznńní. 4. 2017 
Now, we can see a permanent decrease of the need for human work. One of the causes of this can be seen in the disproportion between the knowledge and skills necessary to perform traditional jobs and the knowledge and skills necessary to perform digitized jobs i.e. computerized jobs. Not only jobs themselves but mainly the preparation for working in the innovated and new professions are going through significant changes and there is a strong pressure for speeding up the innovations.

The speed of technological development causes the need for realizing flexible changes across wide fields of a complex and interconnected economy. Those who will not adapt will perish. Many companies realize this and pay great attention to innovative processes, introducing the next generation of technologies and a broad range of complex, multi-disciplinary, physically aware next generation-engineered systems that integrate embedded computing technologies (cyber part) into the physical world.

One of the important issues under discussion now is the fact that "smart factories" create the need for "smarter workers", professionals able to work in a digitized automated and robotized environment. Lee suggests two approaches, namely cyberizing the physical and physicalizing the cyber, for integrating the cyber systems with the physical systems [8].

Many jobs are automatized; however, the responsibility for complex decisions still lies in human hands. We have to pay attention to the increasing amount of data and searching for relevant tools to properly analyse it.

There are also increasing demands on the development of control systems and tools that will make it possible for us to simulate the results of the applied processes. This means a shift from device „operators" to the engineering professions.

The Fourth Industrial Revolution urges us to think creatively about the manufacturing process, value chain, distribution and cus- tomer service processes. In the meanwhile, the future of education emphasizes the immense need to look beyond these areas and strategically utilize the "Internet of Things" to prepare the coming workforce for the challenges ahead [1].

Companies will need to retrain their employees, adopt new work and organization models, recruit for Industry 4.0, and engage in strategic workforce planning [12].

The near future signals the need for urgent solutions of the issues connected with employment, adequate preparation for future jobs, requalification, other professional education etc. In such a rapidly evolving employment landscape, the ability to anticipate and prepare for future skills requirements, job content and the aggregate effect on employment is increasingly critical for businesses, governments and individuals in order to fully seize the opportunities presented by these trends - and to mitigate undesirable outcomes.

Today more than in the past it is very important to increase relationships between governments, educators, training providers, workers and employers and development and research centres in order to coordinate effectively the transformative impact of the technological

development and new technologies implementation on employment, skills and education [15].

One of the key tasks seems to be the necessity of transforming a wide range of traditional professions and occupations. Many prognoses exist which predict the elimination of a large number of professions and existing jobs. The World Economic Forum in the report Future of Jobs predicts that technology could eliminate 5.1 million jobs by 2020 [15].

In 2013, researchers published an academic paper based on a study conducted within the Oxford Martin Program on the Impacts of Future Technology. The authors of the study called "The future of employ-

Paradigmata poznání. 4. 2017 
ment: how susceptible are jobs to computerization?" predicted that the estimating $47 \%$ of total U.S. employment is at risk. Bill Gates predicts that "Software substitution, whether it's for drivers or waiters or nurses ... it's progressing. ... Technology over time will reduce demand for jobs, particularly at the lower end of skill set. ... 20 years from now, labour demand for lots of skill sets will be substantially lower. I don't think people have that in their mental model." Gates says [2].

On the other hand, not only pessimistic scenarios exist in the field of future employment. The optimistic prognoses point to a relatively large potential for the creation of new jobs and professions or a development of jobs or professions, which are only marginal at present. In their work 'Born Digital' John Palfrey and Uri Gasse write, "Digital natives were all born after 1980 when social digital technologies became widely used; they all have access to networked digital technologies and they have the skills to use these." [9]. Thus, easier adaptability of the young generation to the coming changes and the speed of technological development can be expected. We can also expect more flexible promotion of the necessary changes and searching for optimal solutions of the coming issues i.e. opportunities connected with e.g. creation of new jobs or so far non-existent professions. Prof. Dirk Helbing (2014) writes, „Information systems can help us to manage these challenges, and we can create a lot of jobs with them. We just need to create the right settings." [7].

\section{Conclusions}

The contemporary globalized society one of whose characteristics is the process of digitization and coming of new cyber-physical systems brings a wide range of tasks and unanswered questions that need to be systematically monitored and solved. Today more than in the previous periods of human history, it is necessary to perceive reality in tits complexity and interconnection. There is need for using wholesome approaches to problem solving, intensifying the cooperation of the key institutions of the state, science and research, education, industry and services. Flexible education reacting appropriately to progressive changes has to be prepared so that curricula can better reflect the skill sets needed for today etc. As prof., Helbing writes, "New technologies can provide innovative solutions to our 21 st century problems, if they are suitably designed and used" [7].

\section{Bibliography}

1. AbuMezied, A. (2016). What role will education play in the Fourth Industrial Revolution? World economic forum: https://www.weforum.org/agenda/2016/01/whatrole-will-education-play-in-the-fourth-industrialrevolution.

2. Bort, J. (2014). Bill Gates: People Don't Realize How Many Jobs Will Soon Be Replaced By Software Bots. Tech insider: http://www.businessinsider.com/bill-gates-botsare-taking-away-jobs-2014-3?IR=T.

3. CPSE lab. (2016). Cyber-Physical Systems. CPSE lab: http://www.cpse-labs.eu/cps.php.

4. European commission. (2016). Digitising European Industry. Digital single market: https://ec.europa.eu/digital-singlemarket/en/digitising-european-industry.

5. Frey, C., \& Osborne, M. (2013). The future of employment: how Susceptible are jobs to Computerisation? Oxford Martin.

6. Hackett, L. (1992). Industrial revolution. History World: http://historyworld.org/Industrial\%20Intro.htm.

7. Helbing, D. (2014). The Digital Society - A Better Future or Worse? (Introduction of Digital Society). Digital society, Forthcoming.

8. Lee, E. A. (2010). CPS Foundation. Proc. of 47th IEEE/ACM Design Automation Conf.

9. Rowley, A. D. (2010). Digital Natives: Amazing or Alarming? Ivy league insecurities: http://ivyleagueinsecurities.com/2010/09/digitalnatives-amazing-or-alarming. 
10. Russwurm, S. (2015). The Future of Manufacturing -On the way to Industry 4.0. Siemens AG: https://www.munichre.com/site/corporate/get/doc uments_E-

1336615263/mr/assetpool.shared/Documents/0_C orpo-

rate\%20Website/6_Media\%20Relations/Events/P resenta-

tion_SigfriedRusswurm_MonteCarlo2015.pdf.

11. Schwab, K. (2016). The Fourth Industrial Revolution: what it means, how to respond. World Economic Forum:

https://www.weforum.org/agenda/2016/01/thefourth-industrial-revolution-what-it-means-andhow-to-respond.

12. The Boston Consulting Group. (2016). Man and Machine in Industry 4.0. bcg.perspectives: https://www.bcgperspectives.com/content/articles /technology-business-transformation-engineeredproducts-infrastructure-man-machine-industry4/?chapter $=5$.

13. The Levin institute. (2016). What is globalization? Globalization 101: http://www.globalization101.org/what-isglobalization.

14. Webfinance ac. (2016). Globalization. The business dictionary: http://www.businessdictionary.com/definition/glo balization.html.

15. World economic forum. (2016). The future jobs; Employment, Skills and Workforce Strategy for the Fourth Industrial Revolution. Global Challenge Insight Report.

(C) Kasparova E., 2017. 